\title{
Prevention of construction falls by organizational intervention
}

P Becker, M Fullen, M Akladios, G Hobbs

\begin{abstract}
Objectives-Determine if a university based (third party) intervention can improve construction contractor organizational performance to increase use of fall prevention practices and technologies.

Setting-Falls are the leading cause of worker injury and death in the construction industry. Equipment and practices that can prevent falls are often not used appropriately in the dynamic construction work environment.
\end{abstract}

Methods-A contractual partnership between a university and construction contractors created management systems to ensure use of fall protection measures. Audits by university faculty provided accountability for implementing the fall prevention system. Evaluation was conducted by quasiexperimental methodology comparing changes in audit score from baseline to fifth quarter from baseline for intervention and control contractors.

Results-Audit scores improvement was greater for intervention than for control contractor group.

Conclusion-A third party intervention can improve contractor fall prevention performance.

(Injury Prevention 2001;7(Suppl I):i64-67)

Keywords: construction; falls; intervention research; occupational injury

Falls are the leading cause of death in the construction industry. ${ }^{1}$ While the construction workforce represents $5 \%$ of the nation's workforce, it accounts for $49.6 \%$ of fall fatalities. ${ }^{2}$ In West Virginia, the construction industry accounts for more than a third of all (fatal and non-fatal) occupational falls. ${ }^{3}$ A study of 182 claims reported to the West Virginia Bureau of Workers' Compensation reveals that the leading categories for type of work surfaces from which a fall occurred were ladders $(33.5 \%)$ and scaffolds $(13.7 \%) .^{3}$ This same study reports that the five leading reported causes of falls were slippery substance on surface $(17 \%)$, slips or trip (13.9\%), loss of balance $(7.7 \%)$, unsafe equipment $(6.6 \%)$, and a ladder slipping/ skidding $(7.7 \%)$. In this study, $70 \%$ of the claims for compensation from falls reported falling 10 feet or less.

Techniques for preventing construction falls are well known. For example, simple techniques such as minimizing work at heights, proper maintenance, placement and tying off of ladders, and appropriate climbing technique will go far to prevent many of the ladder falls identified in the study cited above. ${ }^{3}$ However, the dynamic nature of the work at a construction jobsite and the transient nature of the workforce make control of simple hazards relatively difficult. ${ }^{4}$ Non-use and improper use of fall prevention equipment are important factors contributing to falls. ${ }^{5}$ If the technical means to prevent many construction falls exists, an effective preventive intervention may be one that maximizes the use of the well known fall prevention technologies.

This intervention research project tested the hypothesis that a university based fall prevention program could change the organizational behaviors of contractor companies to improve their use of existing fall prevention practices and technologies. The design of the intervention research began with several assumptions:

(1) The intervention needed to be relatively intense to yield a measurable outcome. ${ }^{6}$

(2) Providing incentives and marketing for the program were crucial in persuading contractors to adopt an intensive fall prevention program

(3) The establishment and maintenance of accountability systems are an important organizational method to ensure consistent use of safety practices and technologies on construction sites.

\section{Methods}

FALL-SAFE INTERVENTION

Funded by the Center to Protect Workers' Rights and the National Institute for Occupational Safety and Health, the Safety and Health Extension at West Virginia University (WVU) has devised a partnership program between the university and individual construction contractors as a vehicle to prevent construction falls in West Virginia. The thrust of the partnership is to create an organizational intervention that will provide construction contractors with knowledge, a fall hazard control management accountability system, and incentives to decrease fall hazards on their construction sites. Contractors and WVU sign a formal contract (box 1) agreeing that the contractors will conduct fall prevention programs specified by WVU. WVU provides contractors with training, consultation, marketing, and public relations concerning contractors' efforts to prevent falls. The contractor must demonstrate that his/her company is carrying out the required fall prevention programs in order to obtain and maintain the public status of a "Fall-Safe contractor". WVU staff verifies compliance with Fall-Safe programs by quarterly site audits using a hand held computerized audit tool developed specifically for this program. 
The major program elements of the Fall-Safe program include the creation of company-wide and site specific fall prevention written programs, eight hours of fall prevention training for all supervisors and two hours for all workers, designation of company and site fall prevention competent persons, daily inspections of all sites by site supervisors, weekly inspections by company competent persons, and the establishment of a jobsite labor management Fall-Safe committee that conducts monthly inspections.

WVU assumed that this intervention must be marketed through the development of incentives that would improve the earnings of participating contractors. The marketing effort conducted by WVU consisted of three major elements. Major industrial companies that purchase construction services are organized regionally, and WVU obtained the strong

\section{Box 1: Contractual agreement}

In order to decrease falls in the construction industry, WVU Safety and Health Extension and [name of contractor] enter into the following agreement.

\section{Contractor's Name}

(A) Agrees to carry out the Fall-Safe program as described in the participant's handbook.

(B) Agrees to allow and facilitate examination and audit of the contractor's Fall-Safe performance as described in the participant's handbook.

(C) May terminate this agreement with two weeks' written notice.

\section{West Virginia University Safety and Health Extension}

(A) Agrees to provide consultation to participating contractor as described in the participant's handbook.

(B) Agrees to provide training and materials to participating contractor as described in the participant's handbook.

(C) Agrees to audit and report results to participating contractor as described in the participant's handbook.

(D) Authorizes participating contractor to use the designation West Virginia University (WVU) Fall-Safe participant.

(E) May terminate authorization above with a two week written notice if participating contractor is found by WVU Safety and Health Extension staff to be in significant non-compliance with this agreement.

The duration of this agreement is one year. From.. To.

Paul Becker for WVU [signature]

Date

Contractor's Representative [signature]

Date endorsement (by letter to all potential construction bidders) of the Appalachian Construction Users Council. WVU has conducted public relations marketing for Fall-Safe contractors that included press releases concerning Fall-Safe participation issued to contractors' local media, and the use of WVU Fall-Safe signs on participating construction sites. Marketing within construction firms used various Fall-Safe paraphernalia including logo bearing cups, clip boards, carpenters' pencils, and participation cards. Anecdotal response from participating contractors indicated that they perceived that Fall-Safe would lower Workers' Compensation premiums and lead to increased market share for their firms. Positive public relations in their community for Fall-Safe participation was also considered a plus.

\section{MEASURES OF ACCOUNTABILITY}

The Fall-Safe Partnership intervention emphasizes two kinds accountability. The first is the establishment of an accountability system within the contracting company. Participation in the program requires the designation and creation of responsible parties, fall prevention planning before site work, regular inspections, and correction of fall hazards, and a labor management communication and involvement process to ensure that hazards are controlled. In addition to internal accountability, contractors are subject to quarterly surprise inspections by WVU staff of their construction sites. During these inspections, staff conduct audits of program elements such as training, inspections, and meetings. Staff also tour the site and conducts an audit of the control of all fall hazards for that contractor's work. This hazard control audit was based on practices required by Occupational Safety and Health Administration's Fall Prevention Regulation. ${ }^{7}$ Both audits were conducted using a unique software run on touch screen personal portable computers. The two audits generate a percentage score that reflects the percentage of required practices successfully completed by the contractor for all its fall exposures on site. If a contractor drops below $70 \%$ for two successive audits for either the program or site conditions audit, they lose Fall-Safe and the perceived marketing advantage the designation provides. A detailed report is completed and sent to contractors for each site audit with formative information on improvements that can be made.

\section{EVALUATION METHODS}

WVU has nearly completed pilot development and evaluation of the Fall Safe Partnership intervention. For pilot testing, WVU recruited 10 intervention and six control contractors. Selection for participation was based on willingness of a contractor to participate in the project. Contractor types included general contractors, roofers, and heavy and highway contractors. These contractors performed their work in both commercial and industrial settings. Participating contractors reported approximate average yearly hourly employment between 50 and 250 employees. 


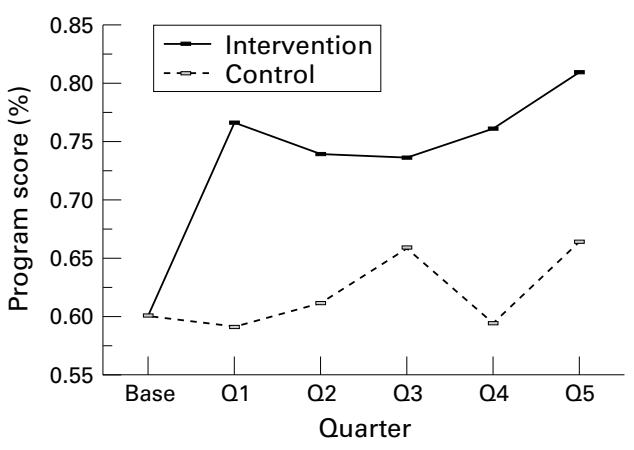

Figure 1 Mean contractor program audit scores by quarter.

For the pilot stage of the research, intervention impact was measured by opinion and activity questionnaires and by site audits conducted by WVU faculty. Questionnaires were obtained from construction company owners, supervisors, and workers for intervention and control contractors, pre-intervention and post-intervention. These same questionnaires will be administered again after 1.5 years of program participation. The audits of site program and site hazard control described above were used to measure changes in contractor performance. Site audits were conducted before program participation (baseline) and quarterly through 1.5 years of participation. This paper reports on the results of the program and hazard control audits through the fifth quarter (out of six) of Fall-Safe participation. In order to limit variation in measures that might be due to temporal factors, variation between contractors for start and end dates for the study period was limited to three months. (Due to lack of work presenting fall hazards for some contractors, baseline and fifth quarter audit scores were obtainable for eight intervention and four control contractors.) Change in audit score from baseline to fifth quarter was calculated for each contractor. Intervention effectiveness was evaluated using analysis of variance (ANOVA) to determine if

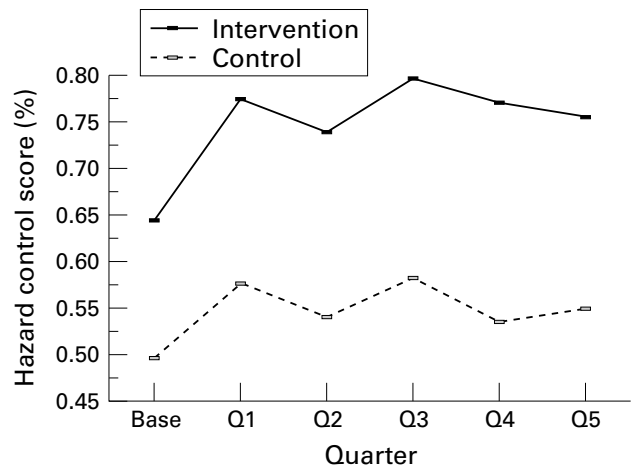

Figure 2 Mean contractor hazard control audit scores by quarter.

Table 1 Analysis of variance for intervention and control contractors change in mean audit scores from baseline to fifth quarter

\begin{tabular}{llll}
\hline Measurement & $R^{2}$ & $p$ Value & No of contractors \\
\hline Mean program score change & 0.21 & 0.02 & 12 \\
Mean field score change & 0.32 & 0.06 & 12 \\
\hline
\end{tabular}

intervention/control status accounted for a significant difference in these change in audit score observations.

Audit data for intervention and control contractors was aggregated and examined (by one way ANOVA) to determine if there was an observed relationship between contractor scores on the program and hazard control audits. ANOVA was also performed on baseline scores to determine if there was any significant difference between the intervention and control groups before conduct of the intervention.

\section{Results}

Figures 1 and 2 illustrate the mean contractor scores for program and hazard control audits over time. Table 1 reports selected metrics from the ANOVA comparing intervention and control groups. The observed difference in mean baseline hazard control scores for intervention and control groups was not significant at $\mathrm{p} \leqslant 0.05$. Intervention contractors were observed to have improved their mean hazard control scores by 11 percentage points, while control contractors improved five points. This difference in change was barely outside the range of significance $(\mathrm{p}=0.06)$. Intervention contractors were observed to improve their mean program audit score by 21 percentage points, while control contractors improved eight points. This difference in change between the two contractor groups was significant $(\mathrm{p}=$ 0.02 ). One way ANOVA indicated a significant relationship between program audit score and hazard control score. Analysis of the audits conducted yielded a coefficient of determination of 0.36 and a $\mathrm{p} \leqslant 0.05$.

\section{Discussion}

While the selection of intervention and control contractors for participation in the study was non-random, the two groups showed no statistically significant difference in either program or hazard control audit scores taken at baseline. The observation that the mean scores for both control and intervention groups showed improvement over time was the unexpected finding of this study. This improvement could represent secular improvement in fall hazard control practices in the industry, or could represent a response to the appearance of a third party person on sites performing the audit activity. (It should be noted that audit results were not reported to control contractors.) This latter hypothesis suggests that future intervention research programs could be designed solely around the use of the computerized audit tool.

Given the improvement of program and hazard control scores in both intervention and control groups, it appears that the Fall-Safe intervention can be credited with improving scores for the intervention contractor group to greater degree than the improvement seen in the control group.

The correlation between site program and hazard control scores is also suggestive that a 
less intensive intervention that focuses on site specific programming might show effectiveness. While a traditional view holds that written safety programs sit in construction trailers and don't impact practices, the site specific nature of the Fall-Safe program plans, and the audit trail required for activities such as training, inspections, and committee meetings may provide support for intervention emphasis on strong site specific safety programming.

Conducting a quasiexperimental intervention in a construction setting presents many program and methodologic problems. Recruiting control participants is difficult, and contamination between the two groups is nearly impossible to prevent. Perhaps the most serious contamination of the control group is the appearance on site of quarterly audit personnel. Another potential source of significant contamination is the possible movement of Fall-Safe trained workers and supervisors from a control to an intervention contractors. (This was not tracked.) Fall-Safe audit faculty did not conduct audits blind to contractor status.

While the use of a control group as part of the study methodology clarified the results of the study, it is important to note that the implementation of the control group methodology in a field setting consumes considerable resources. In construction this problem was exacerbated by the nature of the industry. WVU was not able, for example, to provide training efficiently through regional union hiring halls or apprenticeship programs because of the need for untrained workers (controls). Recruitment of controls was particularly difficult because potential control contractors were subject to the marketing of the economic benefits of Fall-Safe participation.

Finally it should be noted that while the program and hazard control audits seem to measure changes in contractor performance, they have not been validated to measure decreases in fall incidents or injuries.

Given these suggestive results, the Fall-Safe Partnership has been funded to expand to 60 contractors in the next five years. St Paul Insurance and Construction Safety Council will be added to the program performing the marketing, training, consulting, and auditing roles of WVU for contractors in the midwest.

\section{Conclusions}

An intense intervention by an independent third party (State University Extension Service) can improve construction contractor practices that are recognized to prevent construction falls. Accountability systems within the contractor organization and between the contractor and third party appear to be important elements in this observed change. Because of the intensive and intrusive nature of the partnership, marketing the program required both careful planning and considerable resources. Less intensive interventions incorporating some elements of the accountability system might be effectively evaluated in the future.

1 Kisner SM, Fosbroke DE. Injury hazards in the construction industry. F Occup Med 1994;36:137-43.

2 Cattledge GH. Fatal occupational falls in the US construction industry, 1980-1989. F Occup Med 1994;28:647-54.

3 Cattledge GH, Schneiderman A, Stanevich R, et al. Nonfatal occupational fall injuries in the West Virginia construction industry. Accid Anal Prev 1996;28:655-63.

4 Ringen K, Stafford RJ. Intervention research in occupational safety and health: examples from construction. Am $\mathcal{F}$ Ind Med 1995;29:314-20.

5 National Institute for Occupational Safety and Health. Worker deaths by falls. A summary of surveillance findings and investigative case reports. Morgantown, WV: NIOSH, 2000.

6 Goldenhar LM, Schulte PA. Intervention research in occupational health and safety. F Occup Med 1994;36:763-75.

7 Occupational Health and Safety Administration. Occupational safety and health standards for the construction industry. Chicago: CCH Incorporated, 1998: 201-44. 